\title{
BASES EPISTEMOLÓGICAS AKWẼ-XERENTE E APYÃWA: REFLEXÕES SOBRE A EDUCAÇÃO DE JOVENS E ADULTOS EM TERRAS INDÍGENAS
}

\author{
ROGÉRIO FERREIRA ${ }^{1}$ \\ Instituto de Matemática e Estatística, Universidade Federal de Goiás \\ E-mail: rogerio.ferreira@mat.ufg.br
}

\begin{abstract}
RESUMO
Esse artigo intenciona, a partir de uma breve aproximação das bases epistemológicas dos povos Akwẽ-Xerente e Apyãwa, refletir criticamente sobre a atual inserção da modalidade Educação de Jovens e Adultos em terras indígenas. Para tanto, a Educação Escolar Indígena é focada não mais nas diretrizes que julgavam necessárias para retirar do indígena a sua historicidade, mas sim sob a ótica da descolonização dos povos indígenas por meio do fortalecimento das suas culturas. A valorização dos saberes e vontades indígenas como elementos principais de uma educação efetivamente intercultural é refletida como uma necessidade para a inserção política do indígena nos espaços decisórios da sociedade brasileira. A dualidade que sustenta a cultura AkwẽXerente, bem como os modos tradicionais de educar dos Apyãwa procuram fomentar neste texto sensibilidades necessárias ao desenvolvimento de programas educacionais voltados às nações indígenas.
\end{abstract}

Palavras-chaves: educação escolar indígena, EJA, historicidade, currículo.

\section{INTRODUÇÃo}

As experiências que venho acumulando em meio à formação de professores indígenas têm oportunizado o surgimento de reflexões de cunho intercultural acerca do encontro entre os modos de educar tradicionais dos povos indígenas e os modos escolares de educar. Nessas reflexões, uma pergunta recorrente tem sido colocada em foco: como construir uma Educação Escolar Indígena que seja de fato significativa ao povo ao qual se destina? Desse questionamento, origina-se outro, o qual será posicionado no centro das atenções desse artigo: É possível atender às demandas das comunidades indígenas por meio da integração da modalidade de ensino Educação de Jovens e Adultos à Educação Escolar Indígena? Não intenciono aqui encontrar respostas definitivas para essa questão. Afinal, essa seria uma atitude ingênua. O objetivo é promover, de modo crítico, reflexões apoiadas em realidades socioculturais das nações indígenas no Brasil.

Convivendo com diferentes etnias indígenas, pude visualizar organizações socioculturais em que, diferentemente dos modos escolares tradicionais de educar, os atos de aprender e ensinar se dão cotidianamente, por toda a vida, organizados por meio de princípios, valores e olhares diferenciados em relação às visões ocidentais cristãs. Assim, estando atento à questão focal evidenciada no parágrafo anterior, procuro refletir criticamente neste artigo sobre a atual aproximação da modalidade Educação de Jovens e Adultos (EJA) às realidades indígenas. São muitas e complexas as variáveis que afloram dessa aproximação. Entre elas, merecem destaque os embates gerados por meio de uma inconsciência das diferenças existentes entre bases epistemológicas originárias de contextos distintos. A conscientização de que os conhecimentos são múltiplos e dependentes dos contextos em que são germinados é fator essencial para ganhar em profundidade as reflexões que aqui proponho.

O caminho escolhido para a construção desse artigo evidenciará, nas duas próximas seções, exemplos contextualizados, respectivamente, nas realidades socioculturais dos povos Akwẽ-Xerente e Apyãwa. Em seguida, tendo como sustentação os saberes diferenciados apresentados, o artigo trará reflexões relativas à Educação Escolar Indígena sob a ótica de uma possível aproximação à Educação de Jovens e Adultos. Na última seção, serão apresentados alguns caminhos reflexivos acerca da temática proposta por esse texto.

\section{A CUltura AKWẼ-Xerente: UNIVERSO DUAL DE SABERES}

O povo Akwẽ-Xerente vive em uma intensa relação com o Rio Tocantins nas proximidades da cidade de Tocantínia-TO. As poucas historiografias existentes evidenciam que o início da formalidade do ensino, no

1 Rogério Ferreira é professor adjunto do Instituto de Matemática e Estatística, Universidade Federal de Goiás. 
âmbito da sua realidade, encontra-se em um modelo educacional catequético. Logo, nota-se que, já nos passos iniciais da formação dos processos escolares nas terras desse povo, fez-se presente um movimento desestabilizador das significações diretamente ligadas à vitalidade das suas percepções cotidianas. Apesar dos prejuízos decorrentes de uma Educação Escolar descontextualizada, que por décadas vê-se instituída nas terras Akwẽ-Xerente, edifica-se atualmente uma guinada, um momento de reflexão e busca por parte dos professores indígenas que atuam nas aldeias do povo. 0 objetivo atual é transformar esse quadro escolar, o qual foi construído por meio de uma dinâmica de natureza intercultural com clara sobreposição de conhecimentos estrangeiros aos saberes tradicionais.

Os fundamentos do conhecimento Akwẽ-xerente são baseados em uma lógica dual. A sociedade se organiza por meio de metades que só se transformam em unidade no encontro com a parte que lhe falta. Essa organização remete às origens do conhecimento do povo, pois, dos mitos até o que hoje se constrói, a dualidade permanece não só viva, mas significativa aos indivíduos enraizados na cultura. Entretanto, o que foi constituído a partir das maciças interferências provocadas pelos encontros com modos de ser outros, modos alimentados por um imaginário coletivo diferenciado - fruto de concepções culturalmente dinamizadas no continente europeu - nem sempre traz junto a si as fundamentações que se estruturam por meio de metades. Isso aponta para a necessidade de transformar a qualidade das relações advindas dos encontros interculturais. Nesse sentido, quando se intenciona aproximar a Educação de Jovens e Adultos à realidade desta nação indígena, não se pode permitir que haja sobreposição de um saber ao outro e, para isso, é preciso frear as múltiplas forças comumente usadas para esse fim.

Por meio do trabalho etnográfico realizado por Curt Nimuendajú junto ao povo Akwẽ-xerente e publicado em 1942, registra-se que, em tempos passados, as suas aldeias tinham o formato de uma ferradura. Esta possuía uma linha divisória imaginária que deixava, de um lado, os clãs cuja pintura corporal era formada basicamente por circunferências e, de outro, os clãs cujo motivo básico era formado por traços retilíneos. Ao norte da linha habitava a metade exogâmica identificada com a lua e ao sul a metade associada ao sol. A abertura da aldeia se encontrava ao oeste.

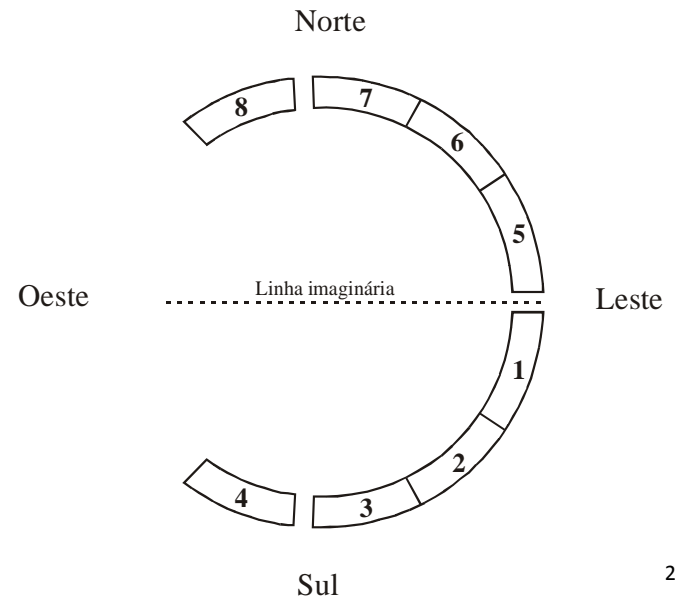

Quatro clãs compunham cada uma das partes e diferenças nos motivos - tamanho e posição - das pinturas corporais. Era o que permitia a identificação visual/pública dos indivíduos da população. Cada clã mantinha relações sociais específicas com o clã que habitava a região simetricamente oposta a da sua morada, estabelecendo, assim, um vínculo formal entre partes em um só tempo distintas e complementares.

A corrida de toras é uma das várias manifestações que bem expressam o saber dual presente na cultura. Trata-se de uma prova que conta com a participação de duas equipes. Cada uma deve conduzir um pedaço de tronco de buriti, por meio de revezamento entre os membros de um mesmo time, por um percurso previamente determinado. A distância total percorrida pode chegar a doze quilômetros. O ponto de chegada, invariavelmente, é o pátio central da aldeia. Homens, mulheres e crianças participam da corrida em momentos e categorias distintas.

A corrida faz parte de um ritual festivo muito valorizado e é organizada por duas pessoas, cada uma pertencente a uma metade exogâmica. A elas cabe percorrer cada uma das moradas da aldeia para informar a hora e o local em que todos deverão se encontrar. Dentre as várias outras tarefas concernentes à função cerimonial a essas pessoas destinada, está a preparação das toras de buriti. Os troncos devem ser cortados de

\footnotetext{
${ }^{2}$ Ilustração simplificada das antigas aldeias Akwẽ-xerente. Esta se baseia na representação original apresentada por Curt Nimuendajú em seu livro "The Šerente" publicado em 1942. Os pares de clãs 1/5, 2/6, 3/7 e 4/8, simetricamente opostos, mantinham entre si relações especiais.
} 
forma que os pedaços fiquem com o mesmo peso e tamanho para que, deste modo, nenhuma das partes fique prejudicada. Pessoas de clãs distintos podem compor uma mesma equipe. Porém, uma vez em um time, o participante não mais pode mudar. Passará, então, a ser sempre identificado como um membro daquele grupo. Deste modo, torna-se parte de uma nova metade no seio da organização social.

O pátio central, palco para a chegada, é o local em que a unidade é estabelecida. Finalizada a prova, as duas toras são posicionadas no pátio e de mãos dadas, em círculos concêntricos, os participantes realizam as danças tradicionais do povo, harmonizadas à situação, chegando, assim, ao ápice proporcionado pelo ritual. Criam um ambiente completo, formam um todo harmônico e, deste modo, mantêm viva a significativa beleza do pensamento dual que se faz presente nas bases dos saberes Akwẽ-xerente.

Para realizar contagens os Akwẽ-xerente - principalmente os indivíduos de mais idade - utilizam os dedos das mãos e dos pés. Iniciam agrupando dois a dois os dedos da mão esquerda. Com a junção dos polegares, passando à mão direita, dão continuidade ao processo. Finalizada esta etapa, apontam para os pés a fim de prosseguir a sequência de ações. Neste instante, recorrem novamente aos dedos das mãos, mas, agora, como se os dedos dos pés estivessem sendo contados. O processo evidencia que a quantidade de dedos, entre mãos e pés, vem mostrar onde os números podem/necessitam chegar. É fundamental dizer que ter o número vinte como limite superior em nada desmerece essa maneira de contar, pois valores maiores não ganhavam sentido na realidade até o momento em que o encontro com uma cultura distinta trouxe para os cotidianos das aldeias elementos que não eram originariamente seus.

Nomes próprios só existem para os números de um a quatro. Os seus significados deixam transparecer a riqueza do dualismo presente na sua linguagem:
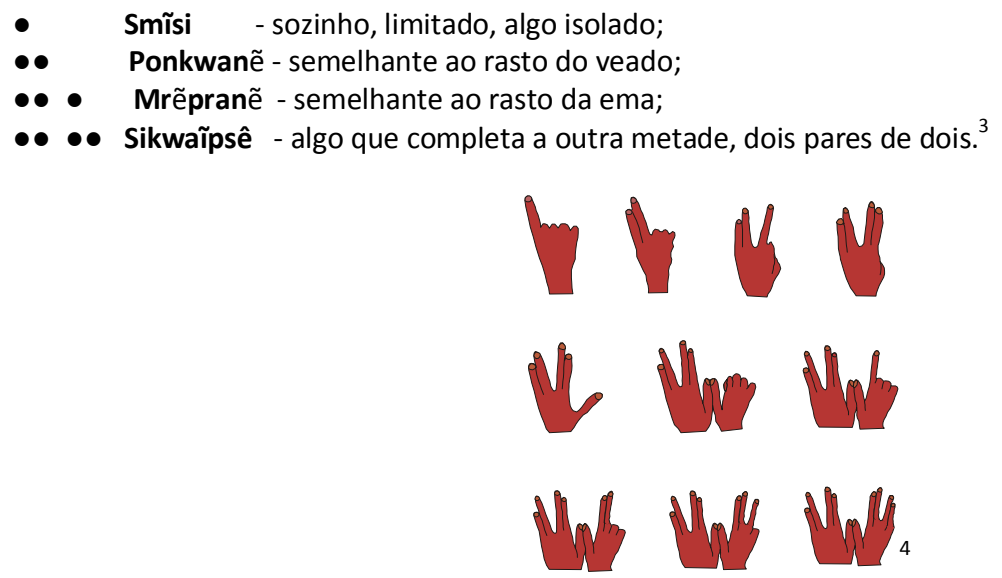

Os números maiores do que quatro (até o número vinte), os quais não possuem uma denominação própria, são integralmente compreendidos por meio da sensibilidade visual. Além disso, se um determinado número não pode ser dividido em uma quantidade exata de pares, então ele não representa algo completo. Logo, apesar das necessidades cotidianas tornarem úteis os números "incompletos", estes, mesmo sendo contemplados pela cultura, não são considerados números "equilibrados". A partir destes saberes próprios da cultura Akwẽ-xerente, cabe a seguinte pergunta de cunho hermenêutico: Como traduzir para outra língua os nomes próprios dados aos seus números? Se uma tradução é realizada sem contextualizar os significados, diretos ou não, associados aos referidos nomes, então ela desrespeita o saber diferenciado, alimenta os movimentos interpretativos de característica etnocêntrica. Esse rol de conhecimentos relacionado à contagem contorna uma manifestação a mais que vem refletir a totalidade da cultura construída por esta nação indígena.

\section{O POVO APYÃWA E OS MODOS TRADICIONAIS DE EDUCAR}

O povo Apyãwa vive na região nordeste do estado do Mato Grosso. A maior parte da população reside na serra do Urubu Branco - município de Confresa-MT. Em seu território, assim como ocorre entre os Akwẽ-Xerente, permanecem vivas sabedorias ímpares, modos de viver alicerçados em elementos de uma cultura milenar praticamente desconhecida pela maioria da população brasileira. Desconhecimento que, secularmente, tem gerado preconceito, violência, descaso, entre vários outros fatores de estirpe equivalente. No entanto, apesar dos rotineiros atos etnocidas presentes na história da invasão européia ao hoje chamado território brasileiro, o povo Apyãwa continua seguindo os seus passos, buscando autonomia, por meio do

\footnotetext{
${ }^{3}$ A obtenção desses significados se baseou em uma análise etimológica realizada pelos professores Nilson Wazase Xerente, Aparecida Kupãrdi Xerente, Edite Smikidi Xerente e por Rinaldo de Mattos - estudioso da língua xerente.

${ }^{4}$ Representação numérica que compõe o conhecimento Akwẽ-xerente.
} 
fortalecimento da sua língua, fazeres, saberes, modos de ensinar, aprender, enfim, por meio de tudo aquilo que Ihes tem oportunizado permanecer de pé em meio à avalanche de atos de violência a que têm sido continuadamente submetidos.

No que tange às práticas docentes atualmente presentes nas escolas Apyãwa, pude acompanhar o desenvolvimento de temas tais como: "Roça tradicional", "Rituais Apyãwa", "Medicina tradicional", "Organização sociolinguística Apyãwa", "Alimentação tradicional”, "Takãra: casa dos homens", "Matemática Tapirapé", "Peixes" e "Arte tradicional". A postura pedagógica que pude observar para o desenvolvimento desses temas não se limita às quatro paredes de uma sala de aula. Entrevistas com os indígenas mais velhos conhecedores da cultura Apyãwa -, confecção de artesanatos, aulas campo às margens do Rio Tapirapé, entre várias outras práticas contextualizadas na realidade da comunidade, foram ações pedagógicas que tive a oportunidade de observar, potencializando a esperança que tenho acerca da construção de modos escolares de educar os quais não venham sobrepor os interesses do povo.

Deste modo, torna-se perceptível que as tradições do povo Apyãwa são fortemente relevadas pelos professores indígenas nos momentos em que estes procuram definir as temáticas a serem trabalhadas dentro e fora de sala de aula. Assim, os Apyãwa têm efetivamente buscado fazer valer seus direitos constitucionais a uma educação diferenciada, contextualizada nos saberes e interesses da comunidade.

A Takãra, tema que recorrentemente tem sido explorado pelos professores Apyãwa, merece maior destaque nesse texto devido a sua característica estruturante na educação dos jovens e adultos Apyãwa do sexo masculino. Trata-se de uma casa cerimonial localizada no centro das aldeias. Constitui um espaço em que ocorrem os rituais, bem como as decisões políticas da comunidade, configurando-se como o local de maior importância para a aprendizagem dos rapazes. As decisões são tomadas coletivamente, surgindo como resultado de conversas e troca de opiniões entre todos os participantes das reuniões. Todos os presentes têm direito à voz. Assim, as decisões ocorrem de modo consensual, quando as ideias passam a convergir para uma opinião comum. Por um lado, é interessante ressaltar que, atualmente, as decisões em torno da Educação Escolar Apyãwa ocorrem no âmbito da Takãra, tornando focal a opinião comunitária no que tange ao presente e ao futuro da escola. Por outro, é preocupante observar que o fortalecimento da escola vem, por sua vez, contraditoriamente, enfraquecendo o poder de decisão da comunidade estabelecido no seio da Takãra. Essa afirmação se pauta no fato de estar diminuindo a frequência das reuniões ocorridas na Takãra no mesmo instante em que aumentam consideravelmente os eventos ocorridos no ambiente escolar. Isso faz surgir uma reflexão a respeito de se estar ou não caminhando para um novo ponto de equilíbrio, favorecendo a sobreposição de um espaço ao outro. Essa questão tem sido motivo de preocupação entre os professores Apyãwa.

Seria a Takãra uma escola tradicional entre os Apyãwa? Coloco essa pergunta em foco não com a intenção de ingenuamente tentar traduzir um saber em outro cujas raízes socioculturais são de natureza diferenciada. Isso recairia em um problema de cunho hermenêutico que exigiria uma atenção que foge aos objetivos desse artigo. A intenção é fomentar no leitor a percepção de que nas mais variadas vertentes, onde se inclui a educacional, as bases epistemológicas de conhecimento e de organização do conhecimento são estruturadas em acordo com o contexto em que são germinadas. Logo, a dinâmica proveniente dos encontros interculturais merece forte atenção para que ideias preconcebidas não venham promover sobreposições de alguns saberes a outros. A construção de procedimentos educacionais de natureza escolar em terras indígenas necessita passar de modo intenso por esse crivo crítico-reflexivo.

A Takãra é construída pelos homens Apyãwa, os quais se agrupam na aldeia em que será desenvolvido o trabalho coletivo. Seis grupos organizam a obra, a saber: Wyraxyga, Wyraxigio, wyraxigoo, Tarawe, Araxa e Warakora. Três grupos cuidam da construção de uma das metades da Takãra e os outros três cuidam da outra metade. Os grupos simetricamente opostos são compostos por pessoas de uma mesma faixa etária, sendo que os dois grupos que trabalham na parte mais central da Takãra são compostos pelos indígenas mais velhos. Em seguida, vêm os grupos formados pelos adultos e, por fim, nas partes mais periféricas, são os indígenas mais jovens que compõem os grupos. Deste modo, a própria construção deste importante espaço favorece a aprendizagem coletiva, visto que os mais jovens, ao mesmo tempo em que assumem responsabilidades de trabalho, contam com a presença dos mais velhos para lhes ensinar, bem como sanar as suas dúvidas. Trata-se de uma aprendizagem social e culturalmente estabelecida. Aprende-se com significado, de modo contextualizado.

É importante destacar que, enquanto trabalham, os Apyãwa cantam. Segundo eles, por meio da música dos trabalhadores, os materiais utilizados na obra ficam mais leves, tornando mais fácil a tarefa de carregá-los em suas costas. A beleza que ronda a organização da sociedade Apyãwa mostra quão cuidadosa deve ser a aproximação da modalidade EJA ao universo cultural do seu povo. Intenciona-se aqui, por meio do contexto específico vivenciado por esta nação indígena, mostrar que qualquer proposta de cunho educacional 
escolar necessita ser construída tendo como fundamentos os saberes da realidade à qual se destina, respeitando sonhos e vontades da comunidade local.

\section{EDUCAÇão DE JOVENS E AdULTOS EM TERRAS INDÍGENAS: REFLEXõES DE NATUREZA EPISTEMOLÓGICA}

A consciência de que o mundo, em suas diferentes vertentes culturais, compõe um mosaico pluriepistemológico é uma condição absoluta para que se possa refletir com máxima isenção sobre o campo da Educação Escolar Indígena. Não é mais aceitável imaginar o encontro entre saberes sob a perspectiva da hierarquia e do conhecimento como um constructo unilinear. Tendo como sustentação os traços epistemológicos diferenciados apresentados nas seções 2 e 3 em relação ao povo Akwẽ-xerente e ao povo Apyãwa, respectivamente, o desenvolvimento desta quarta seção tem por objetivo fomentar o debate acerca da aproximação da modalidade EJA às terras indígenas,.

Apesar de todo o histórico desrespeitoso que acomete o desenvolvimento da educação escolar nos territórios indígenas no Brasil, a construção de uma nova realidade escolar nas aldeias contextualiza-se na atualidade como um meio para os indígenas concretizarem os seus desejos e lutarem contra os mecanismos de poder instituídos no país, os quais rotineiramente fluem contra os seus interesses. Nesse contexto de estranheza cultural, onde os modos de educar tradicionais indígenas foram violentamente sobrepostos, para efetivamente fazer da escola um instrumento favorável ao fortalecimento das culturas Akwẽ-Xerente e Apyãwa, torna-se imprescindível fazer dos seus modos de educar elementos primeiros e basilares para a construção de práticas escolares sintonizadas com os seus valores e sonhos. Ou seja, os conhecimentos construídos pelos povos Akwẽ-Xerente e Apyãwa, as suas historicidades, as suas intenções presentes e futuras devem estar em primeiro lugar na construção de uma educação escolar que reflita efetivamente os desejos de suas comunidades.

Entretanto, colocar esses elementos em primeiro lugar não significa necessariamente excluir dessa escola os conhecimentos que se fazem presentes nos meios urbanos brasileiros. Afinal, para que o indígena possa inserir-se politicamente nos espaços decisórios da sociedade brasileira e mundial, ele precisa ter profundidade crítica sobre os seus saberes de origem, bem como sobre os saberes diferenciados que rotineiramente Ihe acometem. A maioria dos professores Apyãwa e Akwẽ-xerente com os quais tenho tido a oportunidade de dialogar compartilham desse entendimento. Mas não só eles como várias outras lideranças indígenas também possuem essa visão.

Ser instrumento para a interlocução entre os saberes da sociedade indígena e a aquisição de outros conhecimentos: pontilhão de dois caminhos, lado a lado, de conhecimentos indígenas e não-indígenas. (Taukane, in MEC - Referenciais para a Formação de Professores Indígenas, 2002, p. 25)

É fundamental que esse "pontilhão de dois caminhos" venha constituir, prioritariamente, um ambiente de valorização, produção e divulgação dos conhecimentos indígenas, para assim tornar significativa, no contexto cultural envolvente, a riqueza dos saberes que nunca ganharam o devido espaço no seio da sociedade brasileira. Tal ambiente tornar-se-á ainda mais plural e relevante caso traga no seu interior discussões referentes a pontos constantemente velados pelos que dominam. Com esse perfil, poderá levar ao cerne das comunidades indígenas um conhecimento crítico dos problemas que os afligem.

Funda-se, portanto, como uma necessidade para o fortalecimento da Educação Escolar Indígena - o que em princípio poderia parecer contraditório - a construção de um espaço de aprendizagem e ensino que em um só tempo valorize os conhecimentos tradicionais da cultura indígena (na qual se efetiva a construção) e os conhecimentos provenientes do meio cultural dominante. A contradição, chamada a atenção nas palavras antecedentes, perde o sentido ao se revelar que a compreensão do conhecimento não indígena é algo que hoje está em uma relação estreita à sobrevivência dos povos indígenas. Entretanto, não se pode perder de vista que os seus próprios saberes necessitam estar no centro de qualquer ação educacional voltada para a superação da desvantagem sociopolítica em que se encontram.

A partir da breve aproximação realizada aos conhecimentos e valores Apyãwa e Akwẽ-xerente, torna-se vital estar claro: os seus desejos são fundamentais, as suas línguas são fundamentais, seus mitos de origem são fontes que dinamizam as suas culturas, seus universos constituem bases para a construção de uma educação escolar em um só tempo diferenciada e significativa ao seu povo.

Em consonância com esse pensamento, D'Ambrosio afirma que,

A estratégia mais promissora para a educação, nas sociedades que estão em transição da subordinação para a autonomia, é restaurar a dignidade de seus indivíduos, reconhecendo e respeitando suas raízes (D'AMBROSIO, 2001, p. 42). 
Com as bases até aqui erguidas nesse texto, deve estar evidente que a presença da modalidade EJA em aldeias indígenas será incoerente caso não venha a se harmonizar aos contextos socioculturais indígenas. É uma necessidade posicioná-los no centro das atenções dos processos educativos. Logo, a oferta e a organização desta modalidade em território indígena passam necessariamente por um diálogo estreito com a comunidade indígena a que a EJA pretende atender. Uma transposição unilateral de modelos oriundos de outras realidades certamente encontrará obstáculos fortes de ordem sociocultural o suficiente para torná-la inaplicável. As palavras do professor Guarani-Kaiowá Maximino Rodrigues contribuem para o aprofundamento crítico acerca do tema:

Quando entramos em sala de aula a primeira pergunta vem das crianças. Eu não digo 'sentem enfileirados', 'fiquem um atrás do outro'. Jamais faço isso. Eles ficam a vontade. Sentam no chão, ficam olhando para mim com o joelho dobradinho, fazem perguntas. Agora, se não cantarmos e não dançarmos no começo e no final da aula eles não ficam satisfeitos. Uma vez eu fiz isso como experiência. Os outros professores também agiram da mesma forma. As crianças disseram para mim: 'professor, eu achei uma coisa muito estranha hoje'. Eu falei: 'o quê?'. E elas: 'nós não dançamos'. Eu percebi claramente que a fisionomia da criança era triste. Não só de uma, mas de todas. Durante a aula ficavam olhando para mim curiosas, parecia que queriam falar alguma coisa. Foi uma experiência muito grande que eu tive. É fundamental primeiro respeitar o que elas querem para depois estar iniciando o meu trabalho. Muitas vezes eu levo o plano de aula pronto de casa. Mas quando entro na sala ele se modifica. Por quê? Por causa das crianças. (RODRIGUES, 2009, p. 276-7).

É essencial ter cuidado e sensibilidade compreensiva para não fazer da implantação da EJA mais uma maneira desrespeitosa de expandir a dominação/colonização sobre as nações indígenas. Se não houver uma quebra com as práticas que se tornaram comuns no âmbito de instituições, tais como igrejas, organismos governamentais e a própria escola, a presença atual nas aldeias de movimentos educacionais que desconsideram a realidade indígena permanecerá delineando sentidos contrários aos interesses étnicos. Nesse caso, a inclusão político-social do indígena nos espaços de tomada de decisão, bem como o reconhecimento dos seus conhecimentos tornar-se-ão desejos distantes.

Do mesmo modo que não se pode confundir os conceitos de Educação Indígena e Educação Escolar Indígena, também não se pode confundir a EJA com os diferentes modos tradicionais de educar jovens e adultos que se fazem presentes nos contextos indígenas. Os atos de aprender e ensinar entre os Apyãwa, por exemplo, como procuramos mostrar na terceira seção, dão-se durante toda a vida e ocorrem por meio de múltiplas vertentes. Seja no aprendizado voltado à confecção de artesanatos, aos cantos, à alimentação, ao plantio, aos rituais, seja no ensino voltado à construção da Takãra todos ensinam e aprendem por todo o tempo, no âmbito de uma organização sustentada pelos aportes culturais próprios da história do povo. Logo, nesta realidade, não há sentido em vincular os sujeitos da EJA a uma suposta defasagem de cunho educacional escolar.

De modo análogo, essa conclusão se contextualiza no universo dual de saberes do povo Akwẽ-xerente, o qual, a partir de bases epistemológicas germinadas em seus referenciais Sol e Lua, heróis fundadores da cultura do povo fazem-se presentes em cada um dos espaços de vida próprios dos indivíduos que o têm como referência. Assim, uma aproximação da EJA a esta realidade necessita trazer consigo a consciência de que não basta reconhecer as raízes diferenciadas que equilibram a vida do povo, mas, fundamentalmente, fazer da sua epistemologia, que tem a presença da dualidade em todas as vertentes em que sua vida social se organiza, 0 cerne dos diálogos interculturais advindos dos procedimentos educacionais.

O PROEJA - Programa Nacional de Integração da Educação Profissional com a Educação Básica na modalidade de Educação de Jovens e Adultos -, por exemplo, ao buscar integrar a educação profissional e tecnológica à Educação Escolar Indígena, deve ter uma especial atenção com a concepção de trabalho presente em cada um dos contextos indígenas que participam da realidade brasileira. A construção da Takãra, brevemente explicitada neste artigo, mostra a força desta necessidade. Logo, não é mais admissível procedimentos homogeneizadores serem efetivados em comunidades indígenas por meio de sistemas de ensino que desvalorizam conhecimentos germinados em outras realidades culturais. Nesse mesmo sentido, é fundamental perceber que nas tradições escolares muito há das raízes provenientes da antiguidade mediterrânea. Nestas tradições, por sua vez, muito há de uma padronização disciplinar que não reflete o que é tradição nos contextos indígenas. 
Portanto, por meio das argumentações aqui realizadas em uma relação estreita às epistemologias dos povos Akwẽ-xerente e Apyãwa, efetiva-se, neste ponto do texto, a defesa de que só fará sentido a implantação da EJA em contextos indígenas se representantes indígenas participarem ativamente do processo formativo, com poder de decisão e autonomia crítica para intervir no referido processo.

\section{CAMINHOS QUE NÃO SE FECHAM}

A aproximação realizada por esse artigo aos saberes dos povos Apyãwa e Akwẽ-xerente intencionou tornar mais claro, em amplidão, quão diferentes são os modos de interpretar e conhecer dos vários povos por todo o mundo. A diferença, quando visualizada e compreendida sem preconceitos e pensamentos hierárquicos, tende a libertar os olhares para uma atitude dialógica em meio às relações interculturais. Essa atitude representa uma guinada, visto que a Educação Escolar Indígena, em termos de Brasil, foi construída como um reflexo de um projeto maior - nacional e internacional - que deixava claro a impossibilidade da pluralidade, uma vez que era baseado na proposta de unificar as diferenças pela hegemonia, procurando silenciar a questão da diversidade. A isso se dava o nome de integração, termo inadequado, pois o que de fato se intencionava era retirar do indígena a sua historicidade, substituindo-a por outra, julgada superior pelos detentores de poder.

A partir do momento em que essa situação de abuso começou a ser combatida em diferentes partes do mundo por meio da ação de diversos atores, indígenas e não indígenas, a emancipação dos povos indígenas, como povos colonizados, tornou-se uma discussão cada vez mais frequente. Aliado a isto, torna-se fundamental vislumbrar essa emancipação no âmbito da educação, abrindo espaço para um sistema educacional escolar que possa ir ao encontro das particularidades culturais de cada grupo étnico, colocando em primeiro lugar a sua epistemologia, seus desejos e sonhos.

$\mathrm{Na}$ essência dos conhecimentos localmente situados está o sentido da vida - e os princípios da sobrevivência e transcendência - dos indivíduos que neles se alicerçam. Vale relevar que a partir dos conhecimentos de origem, de uma constante crítica/desconstrução sobre os mesmos e da percepção deles enquanto elementos necessários à formação de um modo de compreender o mundo forma-se uma base para a valorização dos diferentes saberes e, também, para a interpretação, sob um enfoque diferenciado do que ocorre na contemporaneidade.

Logo, não há como refletir criticamente sobre possíveis práticas escolares indígenas se, de antemão, não se acredita que elas possam colaborar para a construção de uma organização sociopolítica que valorize os conhecimentos indígenas e, assim, promova o diálogo entre os diferentes. Se esses são fundamentos aceitos, então os programas educacionais voltados às realidades indígenas necessitam estar centrados nas raízes culturais das pessoas que de algum modo participam da instituição escolar. No contexto dos caminhos até aqui erguidos por meio desse artigo, os quais não devem fechar-se, vale destacar ainda que para uma aproximação da EJA às realidades indígenas é necessário atentar-se ao fato de que um grupo, cuja identidade cultural se encontra fragilizada, é facilmente dominado por grupos que têm consciência dessa falta. Necessita-se também dar especial atenção ao fato de que o restabelecimento da dignidade de um indivíduo indígena passa necessariamente pela compreensão dos múltiplos aspectos que envolvem o seu momento histórico.

As estruturas político-pedagógicas presentes nas aldeias precisam estar atentas a esses parâmetros. Caso contrário, os meios educacionais ambientados no continente europeu continuarão descontextualizados nas sociedades que não os edificaram e, assim, permanecerão assumindo o papel de promotores de práticas etnocidas. Diante destas considerações, pode-se afirmar, como último e fundamental ponto a ser fomentado por esse artigo, que em uma formação indígena por meio da EJA deve ser debatida cada uma das necessidades que interferem na concretização de um efetivo protagonismo indígena acerca das decisões nacionais, inclusive - e fortemente - na própria gestão dos programas de Educação de Jovens e Adultos presentes em suas aldeias. Espero que os conhecimentos Apyãwa e Akwẽ-xerente aqui apresentados tenham força suficiente para oportunizar a formação dessa consciência crítica.

\section{REFERÊNCIAS}

D’AMBROSIO, Ubiratan. Etnomatemática: Elo entre as Tradições e a Modernidade. Belo Horizonte: Autêntica, 2001.

MINISTÉRIO DA EDUCAÇÃO. Referenciais para a Formação de Professores Indígenas. Brasília: MEC/SEF, 2002.

RODRIGUES, Maximino; Ferreira, Rogério; Domite, Maria Do Carmo Santos. A Formação de Professores e suas Relações com Cultura e Sociedade: a educação escolar indígena no centro das atenções. In BOLEMA, Ano 22, n 34. Rio Claro, 2009. 